\title{
Predictors of multimorbidity among the Kurdish population living in the Northwest of Iran
}

\author{
N. Aminisani ${ }^{1,2}$, L. Rastgou', S. M. Shamshirgaran ${ }^{2 *}$ (D, P. Sarbakhsh', S. Ghaderi ${ }^{3}$ and M. Hyde ${ }^{4}$
}

\begin{abstract}
Background: There is limited information about the predictors of multimorbidity (MM) among ethnic minority older adults in Iran. This study aimed to examine the impact of sociodemographic and lifestyle factors on the prevalence of MM, among older Kurdish people living in the Northwest of Iran.
\end{abstract}

Methods: The current study was conducted in Bukan city located in West Azarbaijan province in the Northwest of Iran. The data for this study was based on the enrolment phase of a longitudinal study on ageing among the Kurdish population aged 50-94 yearswhich was designed according to the elderly component of the PERSIAN Cohort in Iran. Stratified random sampling was used to select people aged $50+$ from eight health centres in Bukan from Oct 2017 to Dec 2018. Those who accepted the invitation and completed the baseline questionnaire were included in this study $(N=1493$; Response rate $75 \%)$. A range of different factors,including sociodemographic and lifestyle factors as well as self-reported chronic conditions, was obtained by trained interviewers. MM was defined as "coexistence of two or more chronic conditions in the same person". We included a list of 36 diseases/conditions in this analysis. Descriptive analysis and logistic regression were performed to compare the prevalence of MM according to different factors.

Results: Over a third of the participants (36.6\%) had $\geq 2$ chronic conditionsand $15.7 \%$ had $\geq 3$ chronic conditions. Hypertension, diabetes, musculoskeletal conditions, fatty liver, and heart diseases were common chronic conditions. In a fully adjusted logistic regression model, older age $\left(\mathrm{OR}_{\mathrm{adj}}=1.92,95 \% \mathrm{Cl}: 1.48-2.48\right)$, being female $\left(\mathrm{OR}_{\mathrm{adj}}=1.49\right.$, $95 \% \mathrm{Cl}: 1.14-1.94)$, living without aspouse $\left(\mathrm{OR}_{\mathrm{adj}}=1.81,95 \% \mathrm{Cl}\right.$ : 1.34-2.44), and inadequate consumption of fruit and vegetables $\left(\mathrm{OR}_{\mathrm{adj}}=1.33,95 \% \mathrm{Cl}: 1.06-1.67\right)$ were associated with the higher prevalence of MM.

Conclusion: This study found that the prevalence of MM is relatively high among older Kurdishadults. Sociodemographic differences in the prevalence of MM might be of interest tothe health care system,and the prevalence of common chronic conditions in this study may highlight the need forlifestyle modifications in this community.

Keywords: Multimorbidity, Prevalence, Ethnic groups, Diabetes mellitus, Chronic disease

\footnotetext{
* Correspondence: m.shamshirgaran@hotmail.com

${ }^{2}$ Healthy Ageing Research Centre, Faculty of Health Sciences, Neyshabur

University of Medical Sciences, Janbazan Blvd, Neyshabur, Razavi Khorasan 9329774448, Iran

Full list of author information is available at the end of the article
}

(C) The Author(s). 2020 Open Access This article is licensed under a Creative Commons Attribution 4.0 International License, which permits use, sharing, adaptation, distribution and reproduction in any medium or format, as long as you give appropriate credit to the original author(s) and the source, provide a link to the Creative Commons licence, and indicate if changes were made. The images or other third party material in this article are included in the article's Creative Commons licence, unless indicated otherwise in a credit line to the material. If material is not included in the article's Creative Commons licence and your intended use is not permitted by statutory regulation or exceeds the permitted use, you will need to obtain permission directly from the copyright holder. To view a copy of this licence, visit http://creativecommons.org/licenses/by/4.0/ The Creative Commons Public Domain Dedication waiver (http://creativecommons.org/publicdomain/zero/1.0/) applies to the data made available in this article, unless otherwise stated in a credit line to the data. 


\section{Background}

Population ageing has ledto concerns about increased multimorbidity (MM) which is defined asthe "coexistence of two or more chronic diseases in the same individual" [1]. It affects both individuals and health care systems,making this a global health challenge [2, 3].

A range of studies have investigated the prevalence and predictors of $\mathrm{MM}$ in different countries and reported the variableprevalence of MM, ranging from 13.1 to $71.8 \%$ around the world [4]. Results of a systematic review of studies conducted in primary care settings published between 1961 and 2013 included a total of 70, 057,611 patients in 12 countries reported a variable prevalence ranging from 12.9 to $95.1 \%$ [5]. This variation might be explained by the heterogeneity in the data collection methods and the operational definition of MM $[4,6]$. MM has been reported to be associated with poor quality of life [6], increase health care costs and utilization [7], functional decline [8] and death [9].

In Iran the proportion of older adults is rapidly growing, it is predicted that by 2050 the percentage of the aged population will increase to $29.4 \%$ and be comparable with that of the United States [10].Non-communicable diseases (NCDs) area leading cause of morbidity and mortality in Iran $[11,12]$. Despite the high prevalence of chronic disease burden in Iran, research about MM in Iran is scarce, and few studies reported the prevalence of multimorbidity in overall and especially in ethnic minorities and questions have remained regarding the ethnic disparities in accumulation of chronic disease. The results of two studies based on data from the Golestan cohort study; a large-scale cohort study in a high incidence area of oesophageal cancer in northern Iran mainly among the Turkmen ethnic group,reported a prevalence of MM of $19.4 \%$. Moreover, the study showed that women were more likely to present with MM [13, 14 .

The most common chronic diseases reported in Golestan studieswere gastroesophageal reflux disease, cardiovascular diseases, diabetes and chronic obstructive pulmonary disease. Apart age and sex, other factors associated with a higher prevalence of MM were ethnicity, low socioeconomic status, physical inactivity, overweight/obesity, former smoking, opium and alcohol use $[13,14]$. Iran is a multi-ethnic country which includes Persians, Kurds, Lurs, Arabs, Baluchs, Turkmen and Turkic tribeswith different sociocultural values influencing their lifestyles. Kurds are ranked as the third-largest ethnic groups following Persians and Azari people compromising about $10 \%$ of the population. They live mostly in the Northwest and West of Iran, which borders Iraq and Turkey. There is little known about the health and wellbeing of older Kurdish adults, especially as no published data is available about the prevalence of MM among this population [15]. Due to the disproportionate distribution of risk factors as well as the difference in social and cultural values, the prevalence and impact of MM might be different. This study could provide an insight into this problem and could provide important implications for improving primary and secondary prevention efforts to reduce multimorbidity-related health impacts to better plan and deliver care among ethnic groups.

The current study sought to address this lack of evidence by investigating the association between a range of sociodemographic, lifestyle factors and the prevalence of the MM in the Kurdish population. Previous data regarding the prevalence of MM and its related factors are based on the Golestan cohort study, which includes a specific minority group; Turkmen people mainly reside in rural areas. The current analysis was conducted in Bukan, West Azerbaijan Province, in the Northwest of Iran with an estimated population of 194,846 in 2017. To the best of our knowledge, this is the first study of its kind in the world to look at the prevalence of MM amongst Kurds living in Iran.

\section{Methods \\ Study population}

Urban residents of Bukan are almost entirely from the Kurdish-speaking community. Kurdish people follow their sociocultural values and mostly belong to the Sunnibranch of Islam. The data for this study was based on the enrolment phase of the BASwhich was a brief assessment of people aged 50-94 years using a similar questionnaire and measurement as an elderlycomponent of the Prospective Epidemiological Research Studies in IraAn (PERSIAN). In brief, the PERSIAN Elderly Cohort is the first comprehensive longitudinal study on ageing among people aged 50-94 years in Iran aims to assess the different aspects of ageing, monitoring changes in health and wellbeing of older adults using a wide range of data collection including a comprehensive questionnaire on demographic, socioeconomic, lifestyle, physical and psychological aspects, clinical examination, as well as mobility assessment, (www.persiancohort.com). Consideringprevalence of $19.4 \%$ based on the results of Golestan study, 1502 or more were needed to have a confidence level of $95 \%$ that the real value is within $\pm 2 \%$ of the measured/surveyed value. Stratifiedrandom sampling was used to select the study populationfrom eight health centres in Bukan from Oct 2017 to Dec 2018. There was a recently updated list of people aged 50 years and older in these health centres from which we selected the study population. The participants of this study were residents of Bukan who were 50-95 years old without dementia, major depression and or disability which could limit their ability to participate in the study. 
The study staff invited them through a phone call. An interview was scheduled for those who accepted to participate in health centres during official hours. In overall, they contacted 2000 persons, of whom 341 (57\% men and $43 \%$ women) were not interested in taking part in the study. Of those who accepted 166 were not eligible for and were not included. Theoverall response rate was $75 \%(N=1493)$.

The study outcome was thepercentage of the population who reported having MM ( $\geq 2$ chronic diseases). Thiswas based on the study participant's response to the question 'Has a doctor ever told you that you have any of the following health problems? We included a list of 36 diseases/conditions in this analysis including gastrointestinal conditions (peptic ulcer, Chron's disease, ulcerative colitis, fatty liver) heart diseases and hypertension, neurologic diseases (stroke/Transient Ischemic Attack (TIA), epilepsy, Parkinson, migraine, headache, Alzheimer/dementia, MS), musculoskeletal (arthritis, osteoporosis),endocrine conditions (diabetes mellitus, hypo/hyperthyroidism), respiratory diseases (Chronic Obstructive Pulmonary Diseases (COPD), asthma), cancer, and mental disorder (depression, anxiety), and psychological disorders. Because selected noncommunicable diseases (NCDs) such as diabetes, hypertension are recorded for national prevention and control of NCDs programs we were able to validate some of the respondents' self-reported medical conditions against their medical recordsby interviewers under the supervision of a General Practitioner. However, because we used a more comprehensive list of chronic conditions in the survey than are recorded in the medical records we were not able to do this for all conditions.

\section{Data collection and preparation}

Information for this study was collectedvia an interviewer-administered questionnaire. The interviewer also measured BMI via anthropometric height and weight. In analyses, a range of demographic, socioeconomic, lifestyle and clinical factors was examined. Age provided as a continuous variable also was categorised as $50-59,60-69$ and 70 years and over. Marital status was classified into two groups: married/living with a partner and divorced/separated/single/widow. Socioeconomic status indicators included educational qualification categorised as illiterate, and literate. Self-reported incomeadequacy was classified into 3 groups: I don't have a problem, it is enough for basic needs, orit is not enough for basic needs. Smoking behaviour was based on whether respondents to identify themselves as a regular smoker or not. The Physical Activity Scale for the Elderly (PASE) was used to estimate the level of physical activity. It has beenvalidated in previous studies in Iran [16]. The PASE is a brief and specific instrument which has been designed for older adults to estimate physical activity recalled throughoutone week [17]. Frequency and time spent in avariety of activities including leisure time activities (walking; light activities, moderate, or strenuous intensity and muscle-conditioning activities) as well aswork-related activities (in paid or volunteer work) and household activities such as light house-work, yard work, and caring for others were also recorded. After considering the weight for each activity, the final PASE score for the week was calculated based on the sum of all activities, and the mean score was presented. While there are no specific cut points to categorize activity levels, our data were separated into tertile to classify physical activity levels as high $(\geq 121)$, medium (56.5-120.9) or low $(<56.5)$ within each group for descriptive purposes; however the continuous score was used in regression analysis

Body Mass Index (BMI, $\mathrm{kg} / \mathrm{m} 2$ ) was categorised as normal weight $(<25)$, overweight $(25-29.9)$, obese $(\geq 30)$ based on WHO-defined standard cut off points [12].Selfrated health status was categorized as excellent/very good/good, fair/poor. Adequate consumption of fruit and vegetables; was measured by asking questions about the number of raw and cooked vegetableserving/day as well as fresh fruit and juice, then a composite variable was made to classify the number of veg\& fruit consumption per day. It was subsequently categorised into two categories: inadequate less than 5-A-day; adequate 5-Aday.

\section{Statistical methods}

Differences in the characteristics of people with and without MMwere determined with the use of Student's t-test for continuous variables and the chi-square test for categorical variables. We used the logistic regression modelling and calculated the odds ratios (ORs) and 95\% confidence intervals (CIs) for multimorbidity by sociodemographic and lifestyle factors, and built three models; crude, age and sex-adjusted, and adjusted for socioeconomic and lifestyle factors (age, sex, education, marital status, income, BMI, physical activity, smoking, adequate fruit and vegetable intake, self-rated health status). Data were analysed using the STATA statistical package Version14, all estimates were reported with $95 \%$ confidence interval and a significance level 0.05 .

\section{Results}

A total of 1493participants responded to the baseline questionnaireand agreed to be followed up for the further waves of the study. The mean age of participants was $61.6 \pm 9.5$, a majority $(70 \%)$ were less than 65 years of age. Of whom $62 \%$ were women, $82.5 \%$ were married and living with their spouses, $65.6 \%$ were illiterate, (only $6 \%$ had an education level of diploma and higher), only 
$21.7 \%$ reported that they have no financial difficulties and only38.5\% were involved in in-paid work. The majority of participants were overweight/obese (79\%), about $11.7 \%$ reported that they were current smokers, $58 \%$ reported inadequate consumption of fruit and vegetables (less than five serving per day), 25.5\% reported their general health as fair/poor. The meanscore of PASE was $93.3 \pm 61.7$ ranged from 0 to 361 .

Table 1 shows the baseline characteristics of the study participants who were with or without chronic conditions. The overall prevalence of multimorbidity $(\geq 2$ chronic conditions) was 36.6 , and $15.8 \%$ ( $\geq 3$ chronicconditions). As it can be seen relative to those without any chronic conditions, participants with two or moreconditions were older $(P$ value $<0.001)$, women $(P<0.001)$,single/divorced/widowed $(P<0.001)$, had more income difficulties $(P=0.001)$ and had a higher frequency of overweight/obesity $(P=0.086)$. Compared to those without any chronic conditions, participants with MM reported more frequently their health as fair/poor $(P<$ 0.001) (Table 1). Due to the disproportionate distribution of the men and women in our study furtherly, we calculated the weighted prevalence of MM in men was $39.9 \%$ and in women was $61.1 \%$. The difference between unweighted and weighted results was not significant.

The results of a logistic regression adjusted for age and sex indicate that age, marital status, smoking, inadequate consumption of fruit and vegetables, and physical activity were associated with the prevalence of MM $(\geq 2$ chronic diseases) (Table 2). In a fully adjusted model, older age (Odds Ratio ${ }_{a d j}=1.92,95 \%$ Confidence Interval: 1.48-2.48), being female $\left(\mathrm{OR}_{\mathrm{adj}}=1.49\right.$, 95\%CI: $1.14-$ $1.94)$, living without aspouse $\left(\mathrm{OR}_{\mathrm{adj}}=1.81,95 \% \mathrm{CI}\right.$ : $1.34-$ 2.44 ), and inadequate consumption of fruit and vegetables $\left(\mathrm{OR}_{\mathrm{adj}}=1.33,95 \% \mathrm{CI}: 1.10-1.67\right)$ were associated with a higher prevalence of MM. In a fully adjusted model including $M M \geq 3$ chronic diseases as a dependent variable, only age $\left(\mathrm{OR}_{\mathrm{adj}}=2.30,95 \% \mathrm{CI}: 1.66-3.18\right)$ and $\operatorname{sex}\left(\mathrm{OR}_{\mathrm{adj}}=1.90,95 \% \mathrm{CI}: 1.32-2.72\right)$ remained significant (data not shown).

We reported the prevalence of certain chronic diseases to identify multimorbidity in this study population. We found that hypertension (31.5\%), diabetes (17.3\%), fatty liver (14.2\%) and musculoskeletal conditions (21\%) were the four chronic conditions most commonly reported. We found that women had higher rates of the majority of chronic diseases,while men had higher rates of cancer and stroke. We also found that except thyroid conditions, older adults( $\geq 65$ years old) had higher rates of classified chronic diseases (Table 3).

\section{Discussion}

Iran is facing the ageing of the population and a high prevalence of NCDs, as amulti-ethnic country, to deliver better health care and implement prevention strategies, ethnic variation should be taken into account. Little known about the prevalence of $\mathrm{MM}$ and its related health impact,especially in minorities. The current study aimed to estimate the prevalence of multimorbidity and the factors associated with it amongolder Kurdish people in the Northwest of Iran. To the best of our knowledge, this is the first such study of its kind. The overall prevalence of multimorbidity ( $\geq 2$ chronic diseases) was $36.6 \%$ (95\%CI: $34.2-39.1$ ), and the prevalence of $\geq 3$ chronic diseases was $15.7 \%$ (95\% CI:14-17.7) among people aged 50 and over. Previous studies reported the variable prevalence of $\mathrm{MM}$, ranging from 13.1 to $71.8 \%$ around the world [4]. Our prevalence was higher than the Golestan cohort study, which reported a prevalence of $19.4 \%$ [11]. As mentioned previously, the variation in the prevalence of MM might be explained by the heterogeneity in the data collection methods and the operational definition of the MM $[4,6]$. In the current study, the long list of chronic conditions was included than Golestan study. Other possible explanation might be differences between urban and rural lifestyle; ourstudy population were urban residents while the majority were from rural areas in Golestan study. Our study participants were older than Golestan cohort study; the mean age in our study was $61.6 \pm 9.5$. and in that study was $52.1 \pm 9$ years. We should also mention that the selfreported method of data ascertainment in both studies might be suffering from a degree of underestimation, however, we attempted to verify some common conditions through the health records assessment.

There was a significant association between age and multimorbidity, many studies also reported the same results $[18,19]$, but our study found that it was about $30 \%$ of participants aged 50-59 years reported $\geq 2$ coexisting chronic conditions and $11 \%$ reported $\geq 3$ coexisting chronic conditions which merit attention. In this study, MM was higher among women than menwhoare in line with many studies [4]. However, some studies reported no gender differences in patients attending primary care [20-22]. This can be explained by the difference in the study population and the list of diseases included, for example in a study conducted in Switzerland; a list of 75 chronic conditions derived from the International Classification for Primary Care was used.

Overweight/obesity was not associated with MM in the current study, which is opposite to other studies [12, 23]. That might be because the majority (79\%) of our participants were overweight/obese. Overweight/obesity has become a global concern in recent years and is associated with a range of non-communicable diseases such as cardiovascular, diabetes, certain types of cancer and respiratory disease [24]. 
Table 1 General Characteristics of older Kurdish people living in the Northwest of Iran, the Bukan Ageing Study (BAS)

\begin{tabular}{|c|c|c|c|c|c|c|}
\hline Variable & $\begin{array}{l}\text { Number (\%) } \\
\text { total }\end{array}$ & $\begin{array}{l}\text { Prevalence of }<2 \text { chronic } \\
\text { conditions, (\%) rows }\end{array}$ & $\begin{array}{l}\text { Prevalence of } \geq 2 \text { chronic } \\
\text { diseases, } \\
\% \text { row }\end{array}$ & $\begin{array}{l}\boldsymbol{P} \\
\text { value }\end{array}$ & $\begin{array}{l}\text { Prevalence of } \geq 3 \text { chronic } \\
\text { diseases, } \\
\% \text { row }\end{array}$ & $\begin{array}{l}\boldsymbol{P} \\
\text { value }\end{array}$ \\
\hline $\begin{array}{l}\text { Age group (mean +- } \\
\text { SD) }\end{array}$ & $61.6 \pm 9.5$ & $60.3 \pm 8.8$ & $63.8 \pm 10.3$ & $<0.001$ & $65.8 \pm 10.6$ & $\begin{array}{l}< \\
0.001\end{array}$ \\
\hline $50-59$ & 771 (51.6) & 69.8 & 30.2 & \multirow[t]{3}{*}{$<0.001$} & 10.5 & \multirow{3}{*}{$\begin{array}{l}< \\
0.001\end{array}$} \\
\hline $60-69$ & $419(28.1)$ & 63.2 & 36.8 & & 16.0 & \\
\hline$\geq 70$ & $303(20.3)$ & 49.8 & 52.5 & & 28.7 & \\
\hline \multicolumn{7}{|l|}{ Sex } \\
\hline Men & $567(38.0)$ & 70.4 & 29.6 & \multirow[t]{2}{*}{$<0.001$} & 11.1 & \multirow{2}{*}{$\begin{array}{l}< \\
0.001\end{array}$} \\
\hline Women & $926(62.0)$ & 59.2 & 40.8 & & 18.6 & \\
\hline \multicolumn{7}{|l|}{ Marital status } \\
\hline Married* & $1232(82.5)$ & 67.0 & 33.0 & \multirow[t]{2}{*}{$<0.001$} & 13.7 & \multirow{2}{*}{$\begin{array}{l}< \\
0.001\end{array}$} \\
\hline $\begin{array}{l}\text { Single/divorce/ } \\
\text { widow }\end{array}$ & $262(17.5)$ & 46.6 & 53.4 & & 25.6 & \\
\hline \multicolumn{7}{|l|}{ Education } \\
\hline Illiterate & $980(65.6)$ & 61.5 & 38.5 & \multirow[t]{2}{*}{0.035} & 17.8 & \multirow[t]{2}{*}{0.005} \\
\hline Literate & $513(34.4)$ & 67.1 & 32.9 & & 12.1 & \\
\hline \multicolumn{7}{|l|}{ Family income } \\
\hline With major difficulties & $172(11.5)$ & 51.7 & 48.3 & \multirow[t]{3}{*}{0.001} & 22.7 & \multirow[t]{3}{*}{0.029} \\
\hline Just enough & $994(66.7)$ & 66.0 & 34.0 & & 14.8 & \\
\hline No difficulties & $324(21.7)$ & 61.4 & 38.6 & & 15.4 & \\
\hline \multicolumn{7}{|l|}{ Job status } \\
\hline In-paid work & $575(38.5)$ & 71.3 & 28.7 & \multirow[t]{3}{*}{$<0.001$} & 10.1 & \multirow{3}{*}{$\begin{array}{l}< \\
0.001\end{array}$} \\
\hline Retired/no job & $221(14.8)$ & 59.3 & 40.7 & & 20.8 & \\
\hline Housewife & $698(46.7)$ & 58.2 & 41.8 & & 18.9 & \\
\hline \multicolumn{7}{|l|}{ BMI } \\
\hline Less than 25 & $311(20.9)$ & 67.5 & 32.5 & \multirow[t]{3}{*}{0.102} & 15.4 & \multirow[t]{3}{*}{0.210} \\
\hline $25-29.9$ & $556(37.3)$ & 60.2 & 39.8 & & 18.0 & \\
\hline$\geq 30$ & $624(41.9)$ & 63.9 & 36.1 & & 14.1 & \\
\hline \multicolumn{7}{|l|}{ Smoking (current) } \\
\hline Yes & $175(11.7)$ & 58.3 & 41.7 & \multirow[t]{2}{*}{0.133} & 18.9 & \multirow[t]{2}{*}{0.228} \\
\hline No & $1319(88.3)$ & 64.1 & 35.9 & & 15.4 & \\
\hline \multicolumn{7}{|l|}{ Fruit and vegetables } \\
\hline$<5$ serving a day & $846(58.1)$ & 59.6 & 40.4 & \multirow[t]{2}{*}{$<0.001$} & 17.6 & \multirow[t]{2}{*}{0.053} \\
\hline$\geq 5$ serving a day & $611(41.9)$ & 68.6 & 31.4 & & 13.8 & \\
\hline Self-rated health & & & & & & \\
\hline $\begin{array}{l}\text { Excellent/very good/ } \\
\text { good }\end{array}$ & $1113(74.6)$ & 68.5 & 31.5 & $<0.001$ & 12.0 & $\begin{array}{l}< \\
0.001\end{array}$ \\
\hline Fair/poor & $380(24.5)$ & 48.7 & 51.3 & & 27.1 & \\
\hline $\begin{array}{l}\text { Physical activity } \\
\text { (Mean } \pm \text { SD) }\end{array}$ & $93.3 \pm 61.6$ & $91.2 \pm 61.3$ & $96.9 \pm 62.2$ & 0.078 & $92.1 \pm 61.9$ & 0.768 \\
\hline Low $(<56.5)$ & $511(34.2)$ & 66.1 & 33.9 & 0.216 & 17.4 & 0.374 \\
\hline Medium (56.5-120.9) & $485(32.5)$ & 62.9 & 37.1 & & 14.0 & \\
\hline $\operatorname{High}(>=121)$ & 498 (33.3) & 61.0 & 39.0 & & 15.9 & \\
\hline
\end{tabular}


Table 2 Predictors of multimorbidity among older Kurdish people living in the Northwest of Iran, the Bukan Ageing Study (BAS)

\begin{tabular}{|c|c|c|c|}
\hline Variable & $\mathrm{OR}_{\mathbf{1}}{ }^{\mathrm{a}}(\mathrm{Cl} 95 \%)$ & $\mathrm{OR}_{2}^{\mathbf{b}}(\mathrm{Cl} 95 \%)$ & $\mathrm{OR}_{3}{ }^{\mathrm{c}}(\mathrm{Cl} 95 \%)$ \\
\hline \multicolumn{4}{|l|}{ Age (Ref group 50-64) } \\
\hline$\geq 65$ & $2.12(1.69-2.66)$ & $2.16(1.72-2.71)$ & $1.92(1.48-2.48)$ \\
\hline$P$ value & $<0.001$ & $<0.001$ & $<0.001$ \\
\hline \multicolumn{4}{|l|}{ Sex (Ref Men) } \\
\hline Women & $1.63(1.30-2.03)$ & $1.67(1.34-2.10)$ & $1.49(1.14-1.94)$ \\
\hline$P$ value & $<0.001$ & $<0.001$ & 0.003 \\
\hline \multicolumn{4}{|c|}{ Marital status (Ref Married/living with spouse } \\
\hline Single/divorce/widow & $2.32(1.78-3.05)$ & $1.79(1.27-2.27)$ & $1.81(1.34-2.44)$ \\
\hline$P$ value & $<0.001$ & $<0.001$ & $<0.001$ \\
\hline \multicolumn{4}{|l|}{ Education (Ref Illiterate) } \\
\hline Literate & $0.79(0.63--.98)$ & $1.02(0.80-1.29)$ & $0.98(0.76-1.26)$ \\
\hline$P$ value & 0.035 & 0.895 & 0.885 \\
\hline \multicolumn{4}{|c|}{ Income (Ref with major difficulties) } \\
\hline Just enough / No difficulties & $0.58(0.42-0.80)$ & $0.75(0.54-1.05)$ & $0.86(0.61-1.22)$ \\
\hline$P$ value & 0.001 & 0.094 & 0.402 \\
\hline \multicolumn{4}{|l|}{$\mathrm{BMI}^{\mathrm{d}}$ (Ref less than 25 ) } \\
\hline$\geq 25$ & $1.26(0.97-1.65)$ & $1.15(0.88-1.62)$ & $1.18(0.89-1.57)$ \\
\hline$P$ value & 0.084 & 0.311 & 0.257 \\
\hline \multicolumn{4}{|l|}{ Smoking (current) (Ref No) } \\
\hline Yes & $1.28(0.93-1.76)$ & $1.44(1.01-2.05)$ & $1.40(0.97-2.01)$ \\
\hline$P$ value & 0.137 & 0.044 & 0.074 \\
\hline \multicolumn{4}{|c|}{ Fruit and vegetable (Ref $\geq 5$ serving a day) } \\
\hline$<5$ serving a day & $1.48(1.19-1.84)$ & $1.33(1.06-1.66)$ & $1.33(1.06-1.67)$ \\
\hline$P$ value & $<0.001$ & 0.014 & 0.015 \\
\hline \multicolumn{4}{|l|}{ Physical activity } \\
\hline Continuous variable & $1.002(1.00-1.003)$ & $1.002(1.00-1.004)$ & $1.00(1.00-1.004)$ \\
\hline$P$ value & 0.082 & 0.019 & 0.034 \\
\hline
\end{tabular}

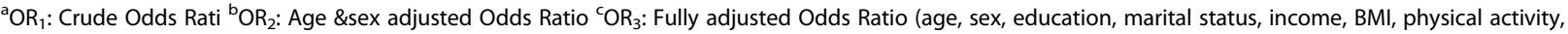
smoking, adequate fruit and vegetable intake, self-rated health status)

${ }^{\mathrm{d}}$ BMI Body Mass Index (Weight $(\mathrm{kg}) /$ Height $^{2}(\mathrm{~m})$

In this study, hypertension, diabetes, fatty liver, musculoskeletal conditions, and heart diseases were prominent conditions. Globally, hypertension as the leading preventable cause of death affects more than $30 \%$ of the adult population [25], and diabetes is an emerging health problem with an estimated about half billionprevalent cases in 2017 which is on the rise throughout the world [26]. Some studies included hypertension in the list of diseases for classification of MM [20] and some not [19]. This is because there is no consistency in the operational definition of MM yet, but diabetes and arthritis have been in the list of common comorbid conditions in published research [13, 20, 21].

\section{Limitations}

Despite its strengths of being the first report of $\mathrm{MM}$ based on a population-based study among Kurdish ethnicity, this study has some limitations; mainly because of the definition of the chronic conditions and its verification. A self-reported method to ascertain the list of doctor-diagnosed chronic conditions seems to underestimate the prevalence of many chronic conditions. Although we attempted to verify the self-reported chronic conditions with the medical records in health centres, a degree of missing information still exits due to undiagnosed conditions. Besides, the difference between the quality of medical records in health centres between developing and developed countries is also another consideration. Comparability between the results of MM in men and women might be used with caution due to the more willingness of women than men to participate in the study and due to the timeframe of the data collection which was during official hours. This might be difficult for some men to attend the health centre and we 
Table 3 Prevalence of common chronic conditions according to gender and age among older Kurdish people living in the Northwest of Iran, the Bukan Ageing Study (BAS)

\begin{tabular}{|c|c|c|c|c|c|}
\hline \multirow[t]{2}{*}{ Chronic disease } & \multicolumn{5}{|c|}{ Prevalence (\%) } \\
\hline & Total & Men, \% & Women, \% & Age $<65, \%$ & Age $>=65, \%$ \\
\hline Hypertension & 31.5 & 28.4 & 33.4 & 27.2 & 41.3 \\
\hline Diabetes & 17.3 & 16.0 & 18.1 & 16.8 & 18.5 \\
\hline Heart Attack & 1.9 & 1.9 & 1.9 & 1.5 & 2.9 \\
\hline Other heart conditions ${ }^{a}$ & 9.5 & 10.2 & 9.1 & 8.6 & 11.5 \\
\hline Fatty Liver & 14.2 & 10.7 & 16.3 & 13.2 & 16.6 \\
\hline Musculoskeletal conditions ${ }^{c}$ & 21.0 & 13.9 & 25.3 & 17.1 & 29.6 \\
\hline Depression/ anxiety & 6.5 & 4.1 & 8.0 & 4.7 & 10.6 \\
\hline Stroke & 1.3 & 1.4 & 1.3 & 0.6 & 3.1 \\
\hline Respiratory conditions ${ }^{\mathrm{b}}$ & 2.8 & 2.1 & 3.2 & 2.6 & 3.3 \\
\hline Hypo/Hyperthyroidism & 3.6 & 1.8 & 4.6 & 4.3 & 1.8 \\
\hline Cancer (any type) & 3.2 & 4.8 & 2.3 & 2.7 & 4.4 \\
\hline Kidney failure & 0.8 & 0.4 & 1.1 & 0.6 & 1.3 \\
\hline Neurological conditions ${ }^{d}$ & 6.1 & 4.9 & 6.8 & 4.4 & 9.9 \\
\hline
\end{tabular}

ancluding Angina, Heart failure, Abnormal heart rhythm

${ }^{\mathrm{b}}$ Asthma, Chronic Obstructive Pulmonary Disease, Chronic bronchitis

${ }^{c}$ Arthritis/ osteoarthritis/ osteoporosis

dEpilepsy, Multiple Sclerosis, Parkinson, Migraine, Headache, Alzheimer

did not have facilities to extend the working hours or arrange a home visit for them. There might also be a degree of selection bias due to non-respondents (25\%). Although this is the first study among Kurdish community living in the Northwest of Iran., these people don't represent all Kurdish people living in Iran. Furtherresearch in other Kurdish cities can contribute to draw abetter conclusion for the prevalence of MM among theKurdish population in Iran.

\section{Conclusions}

This study found that the prevalence of MM is relatively high among Kurdish older adults. Sociodemographic differences in the prevalence of MM might be of interest tothe health care system, and the prevalence of common chronic conditions in this study may highlight the need for lifestyle modification in this community. In addition, to increase the case ascertainment, it is better to integrate information from different data sources.

\section{Abbreviations \\ MM: Multimorbidity; NCDs: Non-communicable diseases; BAS: Bukan Aging Study; TIA: Transient Ischemic Attack; BMI: Body Mass Index; Cl: Confidence Intervals; COPD: Chronic Ostructive Pulmonary Diseases; PASE: Physical Activity Scale for the Elderly; OR: Odds Ratio; ORadj: Adjusted Odds Ratio; ORcrude: Crude Odds Ratio}

\section{Acknowledgements}

This analysis was performed under a thesis grant for the Master's degree from the Department of Statistics and Epidemiology, Tabriz University of Medical Sciences. We gratefully acknowledge people who participated in this study and also the district health department for their collaboration.

\section{Authors' contributions}

The author's contributions were as follows: All authors were involved in design of the protocol and preparation of the Human Research Ethics Committee application and all drafts of the manuscript. NA, LR, SMS, PS and $\mathrm{MH}$ were responsible for data preparation and analysis and SG supported data collection. All authors reviewed and contributed to all drafts of the manuscript. The author(s) read and approved the final manuscript.

\section{Funding}

The present study is funded by Tabriz University of Medical Sciences. The funding body had no role in the design, data collection, analysis, and interpretation of data and in writing the manuscript.

\section{Availability of data and materials}

The data or analysis generated during this study is available from the corresponding author upon request.

\section{Ethics approval and consent to participate}

The study was conducted in accordance with the declaration of Helsinki and had ethics approval from the Tabriz University of Medical Science Ethical Review Committee (Ethical ID numbers: IR.TBZMED.REC.1395.1355) which is a nationally recognized Ethics Committee in Northwest of Iran, once the approval is received from one of the Ethics Committees, the further approval is not required. At the beginning of the study, informed consent was obtained in written forms from all of the participants after thorough explanation of the procedures involved.

Consent for publication

Not applicable.

\section{Competing interests}

Authors have no conflict of interest to declare.

\section{Author details}

'Statistics and Epidemiology Department, Tabriz University of Medical Sciences, Tabriz, Iran. ${ }^{2}$ Healthy Ageing Research Centre, Faculty of Health Sciences, Neyshabur University of Medical Sciences, Janbazan Blvd, Neyshabur, Razavi Khorasan 9329774448, Iran. ${ }^{3}$ District Health Centre, Bukan, Iran. ${ }^{4}$ Centre for Innovative Ageing, College of Human and Health Sciences, Swansea University, Swansea, Wales. 
Received: 4 October 2019 Accepted: 5 July 2020

Published online: 11 July 2020

\section{References}

1. Marengoni A, Angleman S, Melis R, Mangialasche F, Karp A, Garmen A, et al. Aging with multimorbidity: a systematic review of the literature. Ageing Res Rev. 2011;10(4):430-9.

2. Marengoni A, Von Strauss E, Rizzuto D, Winblad B, Fratiglioni L. The impact of chronic multimorbidity and disability on functional decline and survival in elderly persons. A community-based, longitudinal study. Intern Med J. 2009;265(2):288-95.

3. McPhail SM. Multimorbidity in chronic disease: impact on health care resources and costs. Risk Manag Healthc Policy. 2016;9:143-56.

4. Fortin M, Stewart M, Poitras M-E, Almirall J, Maddocks H. A systematic review of prevalence studies on multimorbidity: toward a more uniform methodology. Ann Family Med. 2012;10(2):142-51.

5. Violan C, Foguet-Boreu Q, Flores-Mateo G, Salisbury C, Blom J, Freitag M, et al. Prevalence, determinants and patterns of multimorbidity in primary care: a systematic review of observational studies. PLoS One. 2014;9(7): e102149.

6. Fortin M, Lapointe L, Hudon C, Vanasse A, Ntetu AL, Maltais D. Multimorbidity and quality of life in primary care: a systematic review. Health Qual Life Outcomes. 2004;2:51.

7. France EF, Wyke S, Gunn JM, Mair FS, McLean G, Mercer SW. Multimorbidity in primary care: a systematic review of prospective cohort studies. Br J Gen Pract. 2012:62(597):e297-307.

8. Ryan A, Wallace E, O'Hara P, Smith SM. Multimorbidity and functional decline in community-dwelling adults: a systematic review. Health Qual Life Outcomes. 2015;13(1):168.

9. Nunes BP, Flores TR, Mielke Gl, Thume E, Facchini LA. Multimorbidity and mortality in older adults: a systematic review and meta-analysis. Arch Gerontol Geriatr. 2016;67:130-8.

10. Amini $R$, Ingman, $S R$,. Sahaf, R. Aging in Iran: past, present and future. J Aging Emerg Econ 2013;4(1):17-34.

11. Global burden of Diseases. Washington, Institute of Health Metric and Evaluation; 2014, Available from: http://vizhub.healthdata.org/gbd-compare/. [Cited 2016 Sep 3].

12. WHO. Obesity: preventing and managing the global epidemic. Report of a WHO Consultation (WHO Technical Report Series 894). Available from: https://www.who.int/nutrition/publications/obesity/WHO_TRS_894/en/, 2000.

13. Ahmadi B, Alimohammadian M, Yaseri M, Majidi A, Boreiri M, Islami F, et al. Multimorbidity: epidemiology and risk factors in the Golestan cohort study, Iran: a cross-sectional analysis. Medicine. 2016;95(7):e2756.

14. Alimohammadian M, Majidi A, Yaseri M, Ahmadi B, Islami F, Derakhshan M, et al. Multimorbidity as an important issue among women: results of a gender difference investigation in a large population-based cross-sectional study in West Asia. BMJ Open. 2017;7(5):e013548.

15. Rashidvash V. Iranian people: Iranian ethnic groups. Int J Humanit Soc Sci. 2013;3(15):216-26

16. Borji M, Mothaghi M. The relationship of physical activity, social support and fatigue in elderlies of llam city in 2016. Iranian J of Rehab Res Nurs. 2017; 3(4):A00195.

17. Washburn RA, Smith KW, Jette AM, Janney CA. The physical activity scale for the elderly (PASE): development and evaluation. J Clin Epidemiol. 1993; 46(2):153-62.

18. Akner G. Analysis of multimorbidity in individual elderly nursing home residents. Development of a multimorbidity matrix. Arch Gerontol Geriatr. 2009;49(3):413-9

19. Roberts K, Rao D, Bennett T, Loukine L, Jayaraman G. Prevalence and patterns of chronic disease multimorbidity and associated determinants in Canada. Health Promot Chronic Dis Prev Can. 2015;35(6):87.

20. Britt HC, Harrison CM, Miller GC, Knox SA. Prevalence and patterns of multimorbidity in Australia. Med J Aust. 2008;189(2):72-7.

21. Excoffier S, Herzig L, N'Goran AA, Déruaz-Luyet A, Haller DM. Prevalence of multimorbidity in general practice: a cross-sectional study within the Swiss sentinel surveillance system (Sentinella). BMJ Open. 2018;8(3):e019616.

22. Glynn LG, Valderas JM, Healy P, Burke E, Newell J, Gillespie P, et al. The prevalence of multimorbidity in primary care and its effect on health care utilization and cost. Fam Pract. 2011;28(5):516-23.
23. Meng $Q$, Xie Z, Zhang T. A single-item self-rated health measure correlates with objective health status in the elderly: a survey in suburban Beijing. Front Public Health. 2014;2:27.

24. WHO. Obesity: preventing and managing the global epidemic. 1998.

25. Bloch MJ. Worldwide prevalence of hypertension exceeds 1.3 billion. J Am Soc Hypertens. 2016;10(10):753.

26. Cho N, Shaw J, Karuranga S, Huang Y, da Rocha FJ, Ohlrogge A, et al. IDF diabetes atlas: global estimates of diabetes prevalence for 2017 and projections for 2045. Diabetes Res Clin Pract. 2018;138:271-81.

\section{Publisher's Note}

Springer Nature remains neutral with regard to jurisdictional claims in published maps and institutional affiliations.
Ready to submit your research? Choose BMC and benefit from:

- fast, convenient online submission

- thorough peer review by experienced researchers in your field

- rapid publication on acceptance

- support for research data, including large and complex data types

- gold Open Access which fosters wider collaboration and increased citations

- maximum visibility for your research: over $100 \mathrm{M}$ website views per year

At BMC, research is always in progress.

Learn more biomedcentral.com/submissions 